\title{
Thermal characterization of new, artificially aged and historical leather and parchment
}

Zoltán Sebestyén ${ }^{1}$, Zsuzsanna Czégény ${ }^{1}$, Elena Badea ${ }^{2,3}$, Cristina Carsote ${ }^{4}$, Claudiu Sendrea ${ }^{2}$, Eszter Barta-Rajnai ${ }^{1}$, János Bozi $^{1}$, Lucretia Miu ${ }^{2}$, Emma Jakab $^{1}$

${ }^{1}$ Institute of Materials and Environmental Chemistry, Research Centre for Natural Sciences, Hungarian Academy of Sciences, Magyar Tudósok körútja 2, 1117 Budapest, Hungary

2 Advanced Research for Cultural Heritage (ARCH) Group, National Research and Development Institute for Textiles and Leather (INCDTP), ICPI Division, 93 Ion Minulescu Street, 031215 Bucharest, Romania

3 Department of Chemistry, Faculty Mathematics and Natural Sciences, University of Craiova, 13 A.I. Cuza Street, 200585 Craiova, Romania

${ }^{4}$ National Museum of Romanian History, Victoriei Street 12, 030026 Bucharest, Romania

\begin{abstract}
The aging mechanism of leather and parchment was studied by thermoanalytical methods to understand the effect of the environment on the historical manuscripts and the heritage of libraries and archives. Alkaline and acidic treatments followed by thermal dehydration were applied to achieve chemical changes in the structure of new leather and parchment similar to the slow natural aging of historical samples. Chemical and structural changes during both natural and artificial aging processes were characterized by thermoanalytical techniques. The thermal stability and the evolution profile of the decomposition products under slow heating were studied by thermogravimetry/mass spectrometry (TG/MS). The distribution of the decomposition products of these collagenbased materials under fast pyrolysis was characterized by pyrolysis-gas chromatography/mass spectrometry (Py-GC/MS). It was found that the maximal rate of the thermal decomposition $\left(\mathrm{DTG}_{\max }\right)$ significantly decreases by aging in case of both leather and parchment samples indicating the degree of deterioration. Py-GC/MS has been found to be a suitable technique to sensitively monitor the degradation of the polyphenolic components of the vegetable tannins under natural or artificial aging. It was established that the tannin content of leather is more significantly affected by natural aging and alkaline treatment than the main structure of the polypeptide chains. Principal component analysis (PCA) has been used to find statistical correlations between the experimental data for leather samples. The results of the PCA confirmed that the alkaline treatment and the natural aging processes similarly modify the tannin content of the vegetable tanned leather.
\end{abstract}

\section{Keywords}

Parchment, leather, vegetable tannins, artificial and natural aging, Py-GC/MS, TG/MS, principal component analysis

\section{Introduction}

The skin is composed of three primary layers: epidermis, dermis and hypodermis. The epidermis, the keratin-rich outer layer of the skin, and hypodermis, the subcutaneous fatty tissue, are removed during the fabrication of both parchment and leather [1-3]. The dermis, the collagen and elastin rich inner layer, is the main component of both parchment and leather. The keratin, collagen and elastin are structural proteins built of polypeptide chains whose primary blocks are the amino acids.

The skin processing into leather involves a number of preparatory stages, which are identical to the first stages of parchment preparation, as well as tanning and crusting. The 
purpose of tanning is to achieve more durable materials suitable for a variety of applications, i.e. clothing, footwear, gloves, bookbindings, furniture pieces, military garments, tapestries, boxes, vessels, etc. The tanning procedure permanently alters the chemical structure of the collagen. The tannin molecules stabilize the collagen matrix by linking to the amino acid chains via hydrogen and/or covalent bonding, depending on the tannin type. The oldest system of tanning relies on the chemical action of vegetable extracts containing tannins, while tanning with chromium salts, was introduced at the end of the $19^{\text {th }}$ century. The vegetable tannins are natural polyphenols; the chemical structure of this group of compounds was described by HPLC-ESI-MS/MS method [4].

The parchment is made of animal skin by liming, scraping and drying under tension, but it is not tanned; hence it contains about $95 \%$ collagen [5], whereas the vegetable tanned leather has about $67 \%$ collagen [6]. While leather has always a wide range of applications parchment was mainly used as writing material. It was the unique writing support for both library and then archival documents since the $5^{\text {th }}$ century to the Middle Ages when it was replaced by the cheaper paper.

The collagen-based materials like leather and parchment are sensitive to the environment and especially to sudden and large variation of the storage parameters (e.g. temperature, relative humidity) as well as to $\mathrm{pH}$ and atmospheric pollutants. All these factors, alone or synergistically, have generated different types of deterioration of parchment and leather objects during time. Oxidation, hydrolysis and gelatinization are the main mechanisms of their deterioration [7].

The amino acid sequence of collagen is known in detail [8] and it shows a distinctive domain structure. It is dominated by the amino acid glycine (roughly $1 / 3$ of all residues) and mainly based on the repetition of tripeptides of the type of glycine- $\mathrm{X}_{1}-\mathrm{X}_{2}$, where proline and hydroxyproline are the most frequent amino acids (around 30\%) occupying the $\mathrm{X}_{1}$ and $\mathrm{X}_{2}$ sites. The amounts of alanine, arginine, and glutamic acid are also significant [9].

Applying thermal degradation techniques to analyze different collagen-based materials is not a new idea [10-15]. Budrugeac et al. $[14,16]$ studied the thermal behavior of leather and parchment under different atmospheres by differential scanning calorimetry (DSC). They exposed the materials to high concentrations of chemical pollutants $\left(\mathrm{SO}_{2}\right.$ and $\left.\mathrm{NO}_{\mathrm{x}}\right)$ and observed that the DSC peak was shifted to lower temperature with the aging time and became smaller and broader. It was also reported applying pyrolysis-mass spectrometry (Py-MS) [17] that the major pyrolysis products of peptides and proteins are 2,5-diketopiperazines, which are cyclic dimers of amino acids. Fabbri and coworkers [18] studied the formation of 2,5diketopiperazines during the pyrolysis of linear dipeptides, tripeptides and proteins (e.g., collagen) using pyrolysis-gas chromatography/mass spectrometry (Py-GC/MS) system. They established that the most intense 2,5-diketopiperazine (DKP) peaks in the chromatogram correspond to cyclo(proline-glycine), cyclo(proline-proline) and cyclo(prolinehypdroxyproline). Marcilla and co-workers [19] studied the effect of $\mathrm{NaOH}$ treatment on the thermal decomposition of leather wastes tanned using various tanning agents. They found decreased thermal stability and wider temperature range of decomposition on the $\mathrm{NaOH}$-treated samples by TGA method. Higher amounts of nitrogen-containing products, the occurrence of 1-vinylaziridine and decreased formation of aromatic compounds were detected among the thermal decomposition products by Py-GC/MS technique. Moreover, correlation was found between the electrical properties and the age of the human skin [20].

In this work, the natural aging and the effects of alkaline and acidic aging treatments on leather and parchment were studied by thermoanalytical techniques to understand the aging mechanisms and the response of parchment and leather to the environmental impact. TG/MS and Py-GC/MS were applied to characterize the changes in the structure of new, naturally and artificially aged leather and parchment samples. 


\section{Experimental}

\subsection{Materials}

The new parchment was obtained at INCDTP-ICPI, Bucharest from goat skin, while calf skin and vegetable tannin (extract from chestnut-wood) were used for producing leather. The historical parchment samples were taken from a bookbinding dated 1832, generously offered by the Historical Archives of the University of Turin (Italy). This was the original parchment binding of an examination register at the Arts and Humanities Faculty that was replaced in the 90's by a new bookbinding. The historical leather samples analyzed by TG/MS and Py-GC/MS, were taken from an old gospel from Blaj (Romania) dated 1765 and belonging to the Central University Library "Carol I" of Bucharest (two subsamples H/1 and $\mathrm{H} / 2$ from parts showing different degradation condition), and from a sermon dated 1505 (two subsamples $\mathrm{H} / 3$ and $\mathrm{H} / 4$ from two different parts). The goat parchment and the calf leather were artificially aged by two methods as summarized in Table 1 . The artificial aging treatments consisted of acidic and alkaline treatments followed by thermal dehydration at $120^{\circ} \mathrm{C}$. The new collagen-based materials were soaked in alkaline or acid solutions for 2 days. After the soaking the acid or alkaline treated samples were rinsed with aqueous solutions of $\left(\mathrm{NH}_{4}\right)_{2} \mathrm{SO}_{4}$ or $\mathrm{NaCl}$, respectively. The residual inorganic ions were removed by washing the samples with ion-exchanged water until neutrality tested by an indicator paper. Then the samples were heated at $120^{\circ} \mathrm{C}$ in a ventilated oven for 4 days.

Table 1 - Conditions of aging treatments of leather and parchment.

\begin{tabular}{cccc}
\hline $\begin{array}{c}\text { Treatment } \\
\text { type }\end{array}$ & Conditions & Neutralizing & Drying \\
\hline Alkaline & $4 \% \mathrm{Ca}(\mathrm{OH})_{2}+0.5 \% \mathrm{NaOH}$ & $1 \%\left(\mathrm{NH}_{4}\right)_{2} \mathrm{SO}_{4}$ & $\begin{array}{c}120^{\circ} \mathrm{C} \\
96 \mathrm{~h}\end{array}$ \\
\hline Acidic & $\begin{array}{c}25^{\circ} \mathrm{C}, 48 \mathrm{~h} \\
0.5 \mathrm{M} \text { acetic acid } \\
4^{\circ} \mathrm{C}, 48 \mathrm{~h}\end{array}$ & $0.7 \mathrm{M} \mathrm{NaCl}$ & $\begin{array}{c}120^{\circ} \mathrm{C} \\
96 \mathrm{~h}\end{array}$ \\
\hline
\end{tabular}

\subsection{Methods}

\subsubsection{TG/MS}

The TG/MS system consists of a modified Perkin-Elmer TGS-2 thermobalance and a quadrupole mass spectrometer (Hiden Analytical Ltd., Warrington, UK, model: HAL 2/301 PIC). About $3 \mathrm{mg}$ samples were measured in argon atmosphere at a flow rate of $140 \mathrm{ml} \mathrm{min}{ }^{-1}$. The samples were heated in a platinum sample pan at a rate of $20^{\circ} \mathrm{C} \mathrm{min}^{-1}$ from 25 to $1000^{\circ} \mathrm{C}$. The evolved products were introduced through a glass lined metal capillary heated at $300^{\circ} \mathrm{C}$ into the ion source of the mass spectrometer which was operated at a $70 \mathrm{eV}$ electron energy.

\subsubsection{Py-GC/MS}

Approximately $0.8 \mathrm{mg}$ samples were pyrolyzed at $600^{\circ} \mathrm{C}$ for 20 seconds in helium atmosphere using a Pyroprobe 2000 pyrolyzer interfaced to an Agilent 6890A/5973 GC/MS. The pyrolysis products were separated on a DB-1701 capillary column $(30 \mathrm{~m} \times 0.25 \mathrm{~mm}, 0.25$ $\mu \mathrm{m}$ film thickness). The GC oven was programmed to hold at $40{ }^{\circ} \mathrm{C}$ for 4 minutes then increase the temperature at a rate of $6^{\circ} \mathrm{C} \min ^{-1}$ to $280^{\circ} \mathrm{C}$ with a hold for 5 minutes. The range of $m / z, 14-500$ was scanned by the mass spectrometer in electron ionization mode at $70 \mathrm{eV}$. The identification of the pyrolysis products was based on NIST mass spectral library and 
literature data [18,21]. The peak areas of the total ion chromatograms were normalized to the sample mass and the normalized data were subjected to principal component analysis (PCA) using Statistica 12 software (StatSoft, Inc. Tulsa, Oklahoma, USA).

\section{Results and discussions}

\subsection{TG/MS results}

Fig. 1 shows the TG (a and c) and DTG curves (b and d) of new, alkaline treated, acidic treated and historical leather ( $a$ and $b$ ) and parchment samples (c and d). Leather and parchment behave differently during the heating procedure. The main reason of the different behavior probably lies in the different preparation method of the animal skin to produce leather or parchment. Skin tanning by a vegetable tanning agent from plant extracts [22-24] improves the leather thermal stability and hence its durability and resistance. The collagentannin complex is chemically and thermally more stable $[25,26]$ than collagen in parchment. The yields of the carbonaceous residue of new, artificially aged and historical leather samples (Fig. 1a) are very similar (about $30 \%$ ) at $1000^{\circ} \mathrm{C}$. Lower char yields (about $22 \%$ ) are formed during the decomposition of the parchment samples. The untreated parchment produces the lowest carbonaceous residue $(20 \%)$. The reason for the higher char yield from leather compared to parchment could be the cross-linked collagen structure of leather. The crosslinked network structure of a macromolecular chain favors the char forming reactions under thermal decomposition in inert atmosphere [27]. Furthermore, the increased amount of carbonaceous residue of leather might originate from the residue of the tanning agent as well [28].
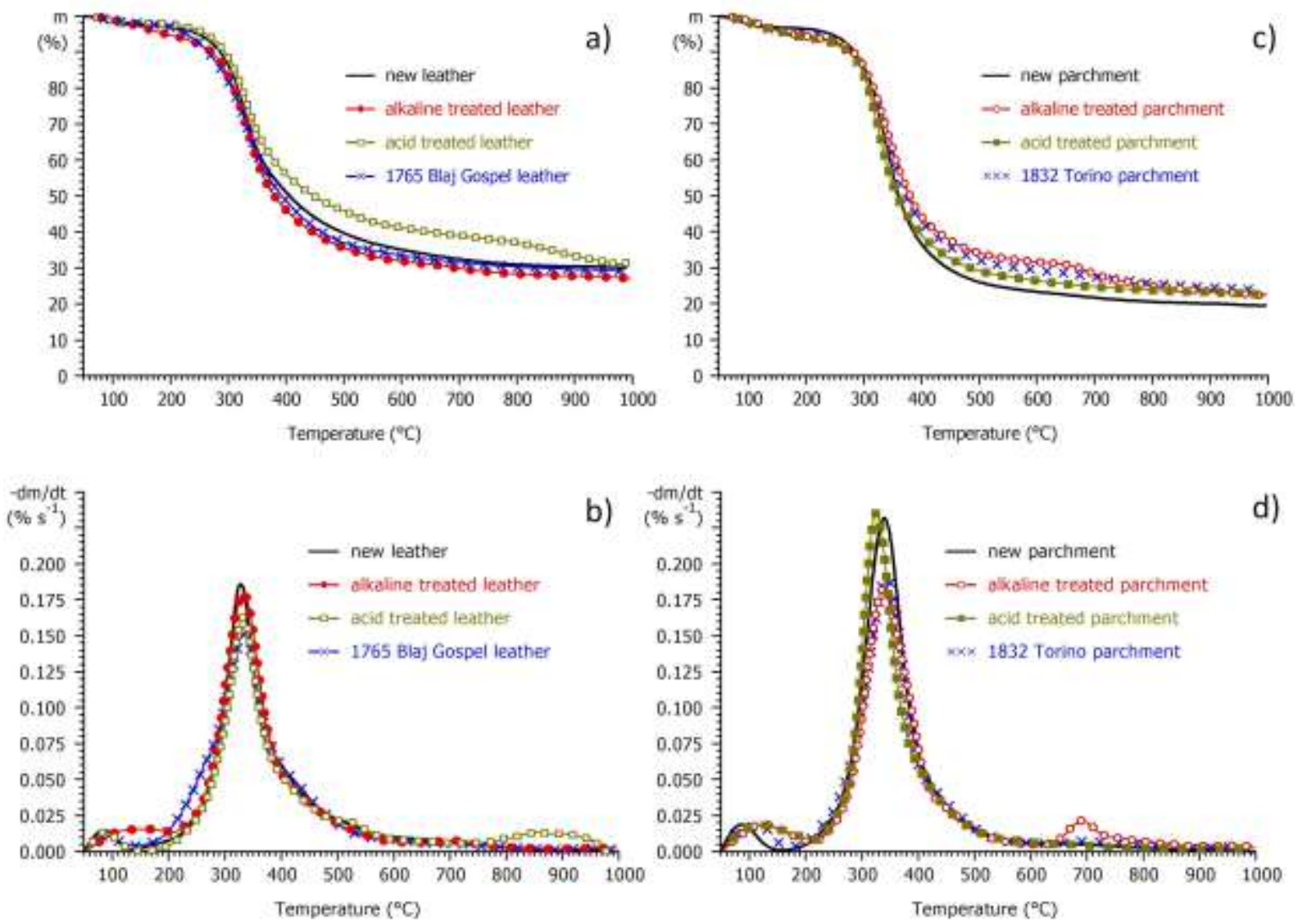

Fig. 1. TG and DTG curves of new, alkaline treated, acidic treated and historical leather (a and b) and parchment samples (c and d). 
Fig. 2 illustrates the evolution of the most important low molecular mass products during the thermal decomposition. The thermal behavior of the alkaline treated and historical samples is similar hence the volatile products of these samples are compared with the new leather and parchment. The first stage of the weight loss of leather and parchment samples (Fig. 1) is due to the evaporation of the adsorbed or not-structured water at around $100^{\circ} \mathrm{C}$, as the $m / z, 18$ mass spectrometric curves demonstrate (Fig. 2). The higher intensity and wider shape of the first water peak indicate the higher water content of the alkaline treated samples, which is apparently bonded to the inorganic residue of the samples. The main DTG peak can be attributed to the thermal decomposition of collagen. The decomposition starts at about $200^{\circ} \mathrm{C}$ and ends at about $550^{\circ} \mathrm{C}$ in both leather and parchment samples [29]. This is the main evolution temperature range of many decomposition products. The decomposition of the naturally aged leather starts at somewhat lower temperature than that of the new and treated ones (Fig. 1b), indicating the decreased thermal stability of the historical leather sample.

The second peak of the evolution curve of water $(\mathrm{m} / \mathrm{z} 18)$ has a maximum at around $300^{\circ} \mathrm{C}$ demonstrating the scission of the hydroxyl groups during the thermal decomposition of leather and parchment. The alkaline treated and the historical samples have more pronounced water evolution below $300^{\circ} \mathrm{C}$, which can be attributed to the oxidation and hydrolysis of the samples. Badea et al. established [30] that artificially and naturally aged samples generally contain destabilized collagen molecules whose capacity to bind water is different by comparison to that of the native triple helix.

The collagen-based materials contain about 8-13\% nitrogen [31] so the formation of significant amount of ammonia $(\mathrm{m} / \mathrm{z}, 17)$ can be expected. Under gradual heating in the thermobalance, the evolution of the $\mathrm{m} / \mathrm{z} 17$ molecular ions is very characteristic indicating the formation of ammonia from the amino and imino groups of the amino acids of leather and parchment samples (Fig. 2). It should be noted that the $\mathrm{m} / \mathrm{z} 17$ ion only represents ammonia since the fragment ion of water was subtracted from the original $\mathrm{m} / \mathrm{z} 17$ curves by the computer. The ion intensity curve of ammonia is higher in case of parchment samples, than that of leather samples. The leather contains relatively high amount of tannin (20-30\%), which does not contain nitrogen so the lower ammonia yield is reasonable. The intensity of the ammonia evolution from the new parchment and leather is as intensive as that from the historical samples certifying that the nitrogen content of the samples did not change significantly during natural or artificial aging. However the shape of the $\mathrm{m} / \mathrm{z} 17$ ion intensity curve became wider in case of aged leather. It may indicate the altered structure of the nitrogen-containing functional groups as a result of aging.

The ion intensity curve of $\mathrm{m} / \mathrm{z} 41$ presents two distinct evolution peaks. The first peak at about $350^{\circ} \mathrm{C}$ can be attributed to the molecular ion of acetonitrile and the fragment ion of pyrrole. The formation of these nitrogen-containing compounds was confirmed by PyGC/MS. The $m / z, 41$ ion is also a regular characteristic fragment ion of aliphatic alkenyl compounds. The release of aliphatic alkenyl and alkyl compounds occurs at higher temperatures: between 400 and $550^{\circ} \mathrm{C}$, which were verified by the evolution of other aliphatic fragments as the $m / z 29$ evolution curve indicates. It can be established in general that the scission of functional groups and the evolution of heteroatom-containing compounds occurs at lower temperatures, while the release of hydrocarbons takes place at higher temperatures.

The increased carbon dioxide $(\mathrm{m} / \mathrm{z} 44)$ formation below $300^{\circ} \mathrm{C}$ indicates the partial oxidation of the samples during the artificial (Fig. 2b) and natural (Fig. 2c) aging of leather samples. Smaller difference can be observed in the yield of carbon dioxide evolving from the parchment samples. Since parchment contains about $95 \%$ collagen it can be inferred that the tannin molecules in leather are involved to a higher degree in the slow natural oxidation process than the collagen. The carbon dioxide peak at about $690^{\circ} \mathrm{C}$ observed in alkaline treated parchment $(\mathrm{m} / \mathrm{z} 44$ curve in Fig. 2e) indicates the decomposition of the inorganic 
carbonate content which apparently originates from the reaction between the alkaline solution and the carbon dioxide from air. The calcium hydroxide residue can easily reacts with the carbon dioxide during the thermal dehydration treatment leading to the formation of calcium carbonate [7].
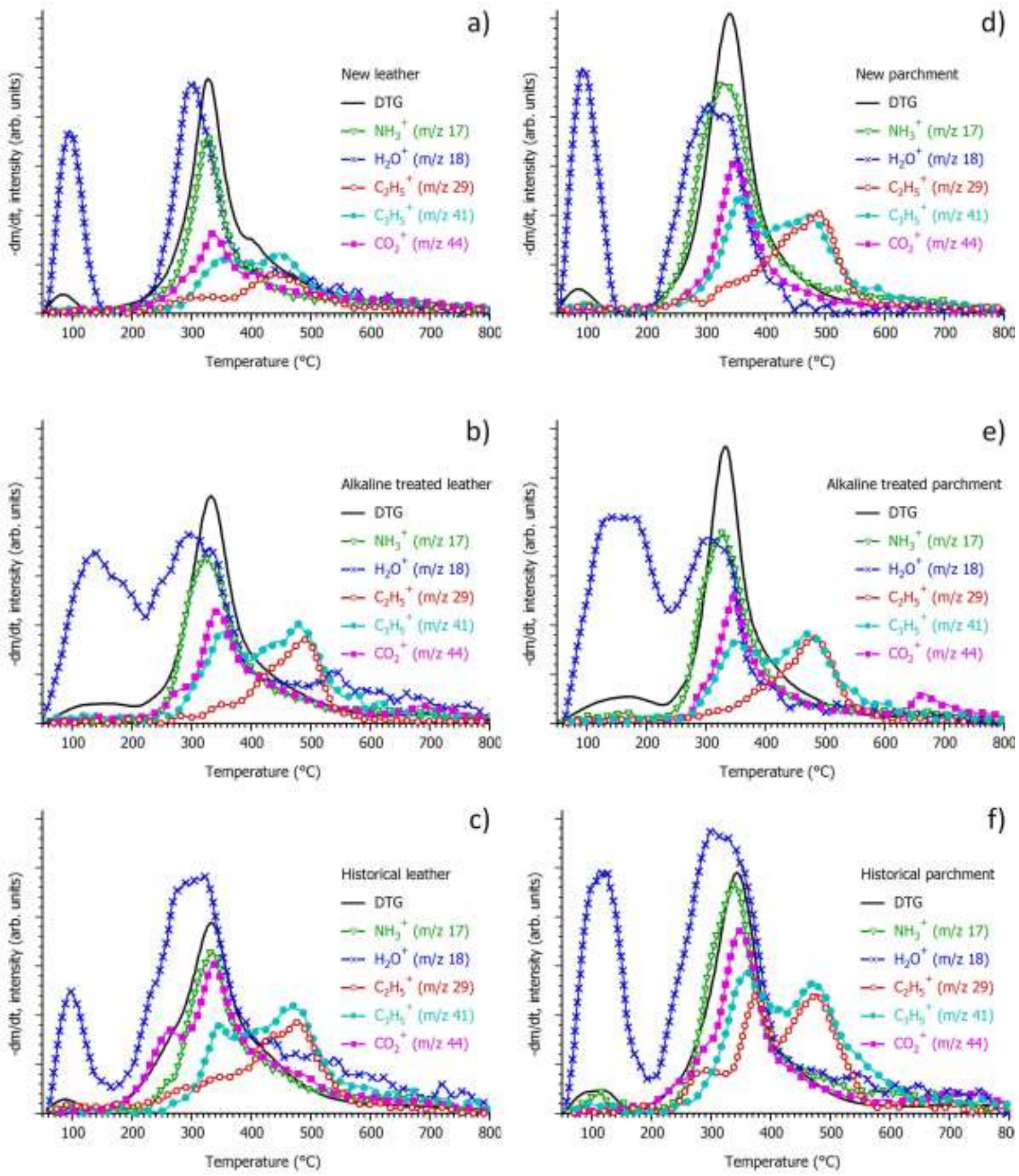

Fig. 2. DTG and a few mass spectrometric curves of new (a and d), alkaline treated (b and e) and historical (c and f) leather and parchment samples.

Fig. 3 shows the evolution curves of a few products which reveal the composition of the amino acid residues of collagen of new leather and parchment samples. The main amino acid constituents of collagen are glycine, proline, alanine, and hydroxyproline. The nitrogen containing aromatic compound, pyrrole $(\mathrm{m} / \mathrm{z}, 67$ curves) can be formed from the pyrrolidine rings of proline and hydroxyproline. The formation of toluene can be attributed to the scission of the side groups of phenylalanine. The leather and parchment samples produce an evolution 
peak of $m / z 47$ ion, which can be attributed to methanethiol, which can be formed from the sulfur-containing amino acid, methionine [26]. It should be however mentioned that collagen is poor in sulfur containing amino acids, only 6-8 methionine residues being present per chain, while cysteine is absent in collagen type I, the constituent of skin [32]. The sulfur content of the leather samples was characterized by the intensive evolution of $\mathrm{SO}_{2}(\mathrm{~m} / \mathrm{z}, 64)$ during the measurements (Fig. 3). The formation of $\mathrm{SO}_{2}$ produced by leather can be either attributed to the remnant sulphur compounds or oxidation of sulphide groups.
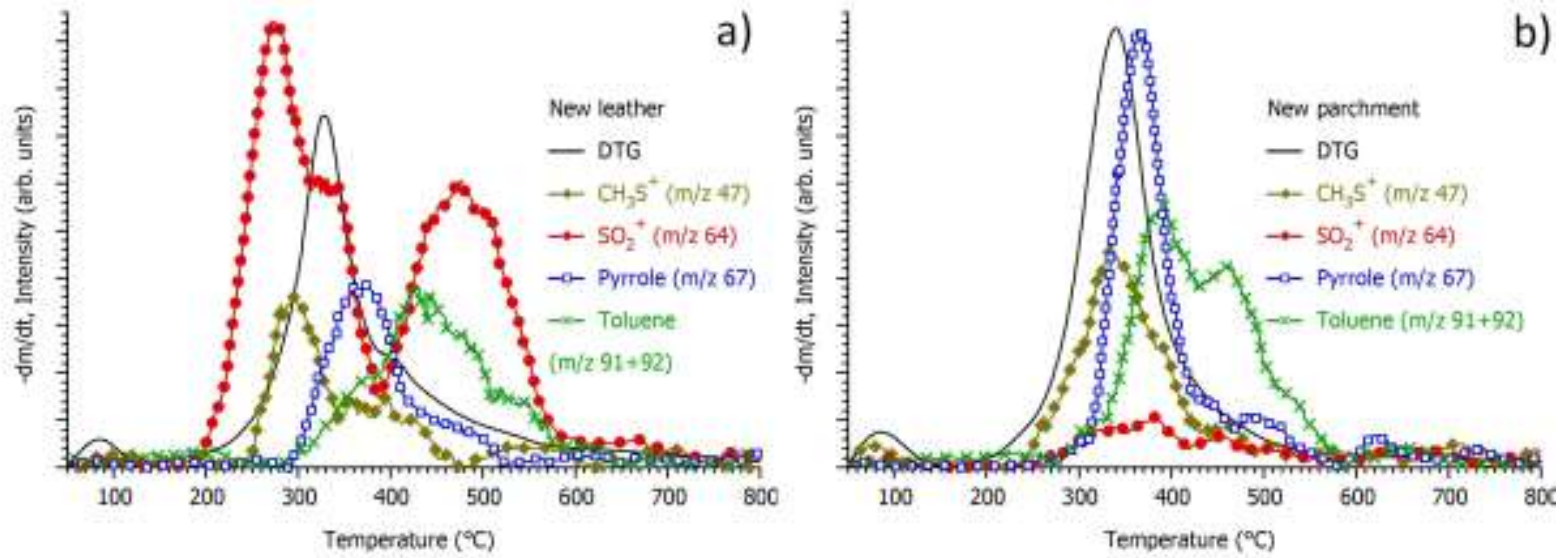

Fig. 3. DTG and some mass spectrometric curves of new leather (a) and new parchment (b) samples.

\subsection{Py-GC/MS results}

Py-GC/MS has been applied to reveal the changes in the pyrolysis product distribution of the leather and parchment samples before and after the artificial and natural aging. The pyrolysis temperature was chosen $600^{\circ} \mathrm{C}$ because the TG/MS results showed that the main steps of the thermal decomposition of the samples ended below this temperature (Fig. 1). The charring represents the only decomposition process taking place above $550^{\circ} \mathrm{C}$. Fig. 4 shows the volatile products originating from new (a), acetic acid treated (b), alkaline treated leather samples (c), and a historical leather from 1765 (d). In Fig. 5 the volatile products evolving from new (a), acidic treated (b) and alkaline treated (c) parchments as well as from a historical parchment from 1832 (d) are shown. The identification of the GC/MS peaks as well as the most intense mass spectrometric fragment and molecular ions are listed in Table 2.

The peaks at lower retention times (peaks \#1-6) correspond to the main lower molecular mass products of the collagen-based materials; they are not separated well on the GC column. However, their evolution was also demonstrated in the TG/MS plots. Ammonia and carbon dioxide can be derived from the amino and carboxyl side groups of the peptide chains, but also from the peptide bonds through more complicated reaction steps. The formation of 1-vinylaziridine (peak \#9) molecules from the alkaline treated leathers was observed previously by Marcilla et al. [19]. This product is common for both the parchment and leather subjected to alkaline treatment and historical samples suggesting similar deterioration patterns.

The main decomposition products of the leather and parchment samples are 2,5-diketopiperazines (DKP) (peaks \#34 and \#37-43). DKPs are cyclic dipeptides formed from the amino acid residues of the samples during pyrolysis. The formation mechanisms of these compounds were discussed in detail by Voorhees et al. [17] and Fabbri et al. [18]. Proline-glycine DKP (pro-gly, peak \#40) is the most abundant among all, in accordance with the fact that glycine and proline are the major constituents of collagen. Only traces of gly-gly type DKP (peak \#34) were found among the decomposition products, although each third amino acids of the collagen peptide chain is a glycine. The very small yield of this DKP is 
explained by the fact that two glycine residues do not link to each other in the collagen polypeptide chain. As Table 2 demonstrates, DKP pyrolysis products were formed from the four most abundant amino acid residues, i.e., glycine, proline, alanine, and hydroxyproline. The other two important components of collagen, namely glutamic acid and arginine do not produce DKP products as reported by Hendricker and Voorhees [33] due to the inhibition of the DKP ring formation by these amino acids. The high yield of carbon dioxide and ammonia measured by TG/MS indicates that these amino acids probably lose their amino, imino and carboxylic side groups during pyrolysis. Comparing the intensity of the identified DKP pyrolysis decomposition products of new, artificially aged and historical leather and parchment samples, it can be concluded that the yield does not vary significantly. This proves that neither the applied aging treatments nor the natural aging process alter the main amino acid chain structure significantly.

The intensity of phenol (peak \#16) and phenol derivatives (peaks \#17, \#19, \#27, \#31 and \#33) is significantly higher among the decomposition products of leather than parchment. Resorcinol (peak \#31) and 1,2-benzenediol (peak \#27) are the most abundant phenolic products released from the new and acid-treated leather samples, however we could not detect these compounds during the pyrolysis of parchment samples. The phenolic compounds are the main decomposition products of the vegetable tannins used to produce leather [34,35]. As Fig. 4 shows the acidic treated and the new leather samples evolve similar yield of phenolic pyrolysis products. However, 1,2-benzenediol and resorcinol are almost absent in the pyrograms of the alkaline treated and historical samples. This observation indicates that the tannin molecules are highly involved in the aging process, both artificial and natural.

The aromatic hydrocarbon compounds (peaks \#10, \#18, \#20, \#22, \#23 and \#28) represent another group among the decomposition products of leather and parchment. The amino acid residues of collagen contain phenyl side groups that can be the source of these products. In general, it can be observed (Fig. 4 and 5) that the formation of aromatic hydrocarbons from the leather is more intensive than from parchment samples. The higher amount of aromatic products from leather can be explained by the decomposition products of the polyphenolic tanning agents.

Pyrrole (peak \#11) and its derivatives (peaks \#12-14) are the products of the thermal decomposition of proline and hydroxyproline units. These are the most dominant amino acid building blocks after glycine in the collagen structure. Acetonitrile (peak \#7) and propanenitrile (peak \#8) as well as benzenepropanenitrile (peak \#25) and pyrrole-carbonitrile (peak \#26) have nitrile functional groups. These molecules are also formed as a result of the amino acid chain scission and hydrogen transfer.

The pyrograms of new and treated leathers as well as parchments show a small peak, pyrrole-2-carboxamide (peak \#30), which is an interesting pyrolysis product because of the presence of the original peptide bond.

Comparing the changes in the composition of the pyrolysis products of leather (Fig. 4) and parchment (Fig. 5), it can be established that the natural or artificial aging have much more characteristic effect on the distribution of the decomposition products of leather than that of parchment. The intensity of the decomposition products originating from the tanning agent changed to a great extent, while the yields of the pyrolysis products of the amino acid chain do not alter significantly. As parchment is almost pure collagen and does not contain tannin, significant changes in the chemical structure cannot be detected under the applied artificial or natural aging processes by pyrolysis technique. However, Py-GC/MS is suitable to sensitively monitor the degradation of the polyphenol tannin components in the leather samples exposed to acidic or alkaline treatment as well as to natural aging. The alkaline treated and historical leathers release significantly smaller yield of phenol derivatives during 
pyrolysis than the new and acidic treated samples. This observation can be explained by cross-linking of the tanning agent during the alkaline and natural aging.
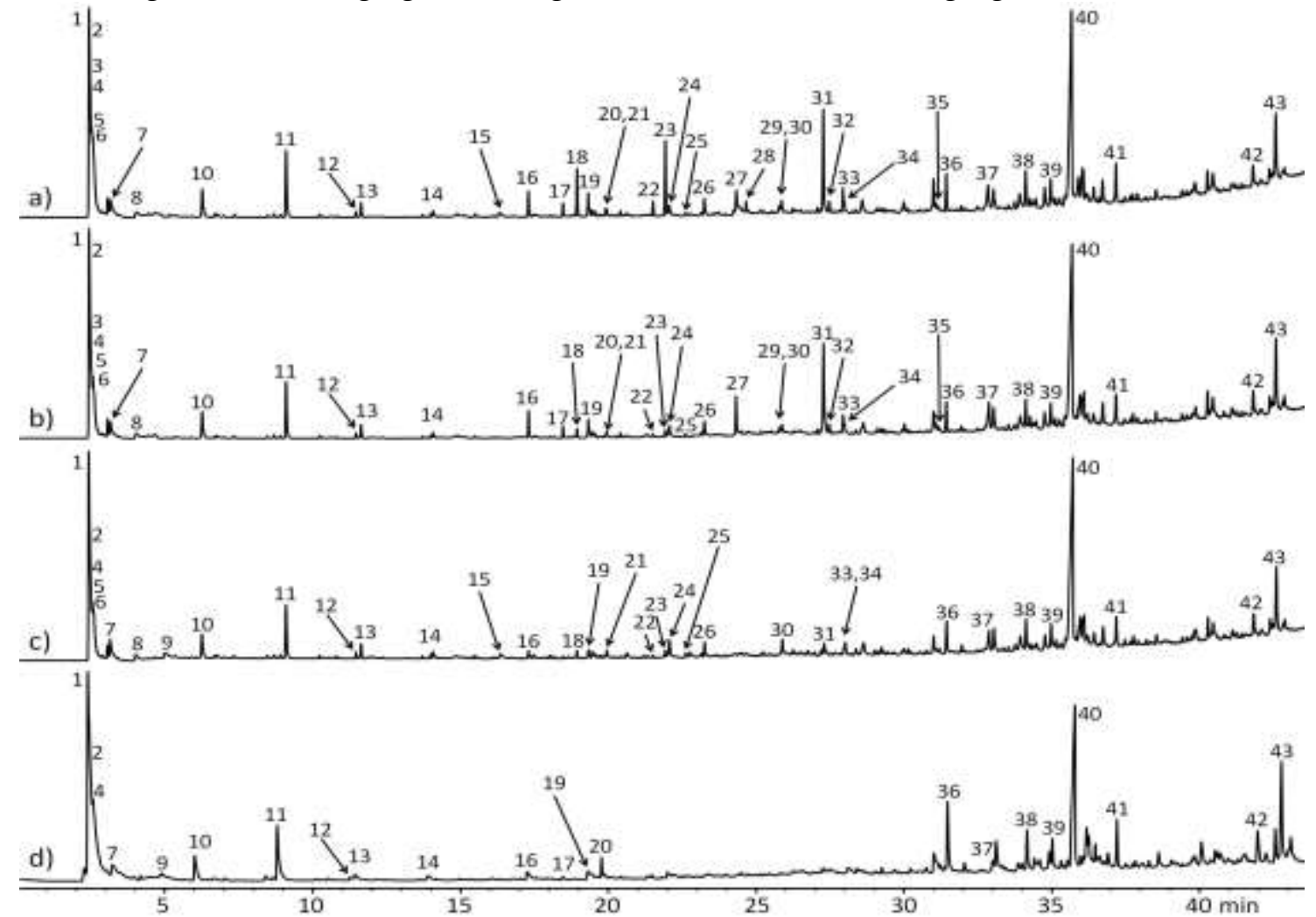

Fig. 4. Pyrograms of new (a), acetic acid treated (b), alkaline treated (c) and historical (d) leather samples. Numbered peak identities are given in Table 2.
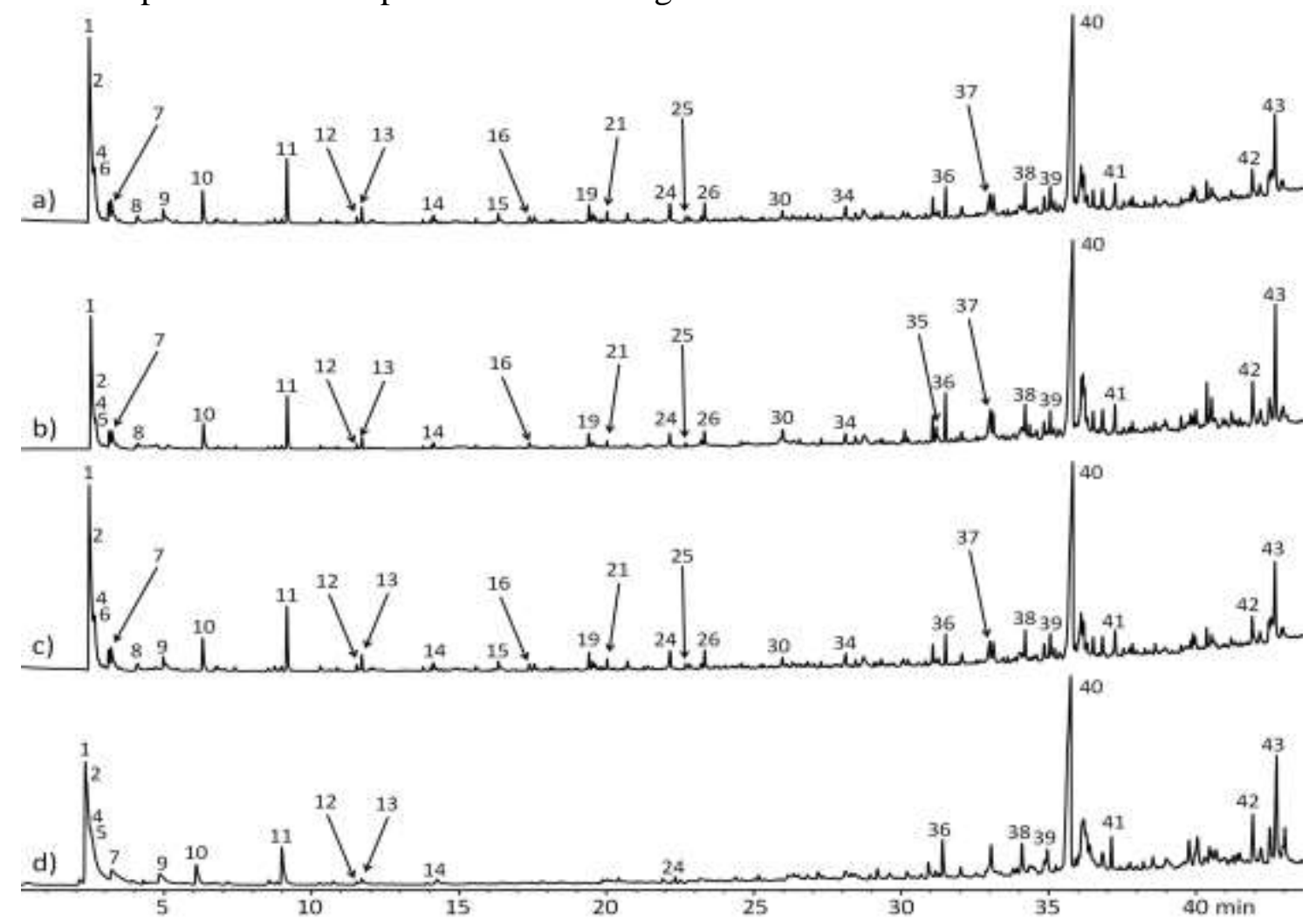

Fig. 5. Pyrograms of new (a), acetic acid treated (b), alkaline treated (c) and historical (d) parchment samples. Numbered peak identities are given in Table 2. 
Table 2 - The main decomposition products released in the Py-GC/MS experiment of new, pretreated and historical leather and parchment samples. Peak numbers refer to Fig. 4 and Fig. 5.

\begin{tabular}{|c|c|c|c|c|}
\hline No. & Ret. Time (min) & Compounds & Most abundant ions (m/z) & MW (Da) \\
\hline 1 & 2.45 & $\mathrm{CO}_{2}$ & 44,28 & 44 \\
\hline 2 & 2.48 & ammonia & 17,16 & 17 \\
\hline 3 & 2.53 & $\mathrm{SO}_{2}$ & 48,64 & 64 \\
\hline 4 & 2.57 & $\mathrm{H}_{2} \mathrm{O}$ & 17,18 & 18 \\
\hline 5 & 2.60 & $\mathrm{HCN}$ & 27,26 & 27 \\
\hline 6 & 2.61 & methanethiol & $47,48,45$ & 48 \\
\hline 7 & 3.17 & acetonitrile & $41,40,39$ & 41 \\
\hline 8 & 4.02 & propanenitrile & $28,54,55$ & 55 \\
\hline 9 & 4.91 & 1-vinylaziridine & $41,69,68,42$ & 69 \\
\hline 10 & 6.27 & toluene & $91,92,65$ & 92 \\
\hline 11 & 9.11 & pyrrole & $67,39,41$ & 67 \\
\hline 12 & 11.48 & 3-methylpyrrole & $80,81,53$ & 81 \\
\hline 13 & 11.65 & 2-methylpyrrole & $80,81,53$ & 81 \\
\hline 14 & 14.07 & 2-ethylpyrrole & $80,95,53$ & 95 \\
\hline 15 & 16.27 & 2-pyrimidinamine & $94,67,41$ & 94 \\
\hline 16 & 17.31 & phenol & $94,66,65$ & 94 \\
\hline 17 & 18.48 & 2-methylphenol & $108,107,79$ & 108 \\
\hline 18 & 18.95 & naphthalene & $128,102,64$ & 128 \\
\hline 19 & 19.33 & 4-methylphenol & $107,108,79$ & 108 \\
\hline 20 & 19.81 & 2,5-bis(1,1-dimethyl)naphthalene & 225,240 & 240 \\
\hline 21 & 19.96 & benzyl nitrile & $117,90,116$ & 117 \\
\hline 22 & 21.53 & 1-methylnaphthalene & $142,141,115$ & 142 \\
\hline 23 & 21.95 & 2-methylnaphthalene & $142,141,116$ & 142 \\
\hline 24 & 22.08 & succinimide (2,5-pyrrolidinedione) & $99,28,56,70$ & 99 \\
\hline 25 & 22.64 & benzenepropanenitrile & $91,131,65$ & 131 \\
\hline 26 & 23.26 & pyrrole-2-carbonitrile & $92,65,41$ & 92 \\
\hline 27 & 24.34 & 1,2-benzenediol & $110,64,81$ & 110 \\
\hline 28 & 24.68 & 2,3-dimethylnaphthalene & $156,141,115$ & 156 \\
\hline 29 & 25.81 & 2,2'-bifuran & $134,78,105$ & 134 \\
\hline 30 & 25.88 & pyrrole-2-carboxamide & $110,94,93$ & 110 \\
\hline 31 & 27.29 & resorcinol & $110,82,81$ & 110 \\
\hline 32 & 27.49 & 3-methylbenzothiophene & 147,148 & 148 \\
\hline 33 & 27.95 & 3,5-dihydroxytoluene & $124,123,95$ & 124 \\
\hline 34 & 28.00 & glycine-glycine DKP* & $71,86,114$ & 114 \\
\hline 35 & 31.14 & 2,3-dimethylpyrrolo(2,3b)pyrazine & $146,147,132$ & 147 \\
\hline 36 & 31.45 & pyrocoll & $186,93,65,130$ & 186 \\
\hline 37 & 32.86 & glycine-alanine DKP * & $85,128,57,43$ & 128 \\
\hline 38 & 34.14 & proline-alanine DKP $*$ & $70.97,125,168$ & 168 \\
\hline 39 & 34.98 & proline-alanine DKP * & $70.97,125,168$ & 168 \\
\hline 40 & 35.68 & proline-glycine DKP * & $111,154,83,70$ & 154 \\
\hline 41 & 37.19 & proline-proline $\mathrm{DKP} *$ & $70,194,96,138$ & 194 \\
\hline 42 & 41.82 & proline-hydroxyproline DKP * & $210,70,86,124$ & 210 \\
\hline 43 & 42.59 & proline-hydroxyproline DKP * & $210,70,86,124$ & 210 \\
\hline
\end{tabular}




\subsection{Principal component analysis (PCA) of the leather samples}

PCA of the pyrolysis data has been applied to compare the effect of the artificial and natural aging process on the leather samples. PCA provides the linear combinations of the original parameters (Factors) to present the similarities and the differences between the samples. In the original calculation the normalized peak areas of 23 pyrolysis products (mostly the aromatic compounds and not the DKPs) have been used. However, some of the loadings characterized the same properties so the model could be simplified. Finally, 12 pyrolysis products have been used in the calculation. During the calculation no factor rotation was applied because the difference between the samples is visible in Fig. 6. Factors 1 and 2 describe $62.70 \%$ and $24.22 \%$ of the total variance, respectively. These two principal components can satisfactorily characterize the major differences between the samples. The numbers in the loading plot (Fig. 6a) correspond to the peak numbers given in the Table 2 . The pyrolysis products resorcinol (\#31), bifuran (\#29), 2-ethylpyrrole (\#14), 1methylnaphthalene (\#22) and 1-vinylaziridine (\#9) correlate with Factor 1. These are mainly decomposition products of the vegetable tanning agents $[34,35]$. The decomposition products benzylnitrile (\#21), 3-methylpyrrole (\#12), benzenepropanenitrile (\#25) and pyrrole-2carbonitrile (\#26) contribute mainly to Factor 2. These products mostly originate from the polypeptide chain of collagen.

Figure $6 \mathrm{~b}$ demonstrates that the analyzed leather samples are located in three well separated groups in the score plot. The new (R/1 and $\mathrm{R} / 2)$ and the acidic treated samples (Ac/1 and Ac/2) belong to the same group, indicating that the acidic treatment doesn't modify significantly the composition of the pyrolyzate comparing to the untreated leather sample. Another group was formed from the historical leather samples $(\mathrm{H} / 1, \mathrm{H} / 2, \mathrm{H} / 3$, and $\mathrm{H} / 4)$ on the left side of the sore plot and the alkaline treated samples (Al/1 and $\mathrm{Al} / 2)$ located on the same side. These samples are separated from the reference and acidic treated samples by Factor 1 . As Factor 1 is strongly determined by the decomposition products of tannin, this observation indicates that apparently the alkaline treatment modifies the tannin content of leather similarly to the natural aging process. This should be however further investigated as the origin of the tannins used for manufacturing the two historical samples is unknown. In spite of this observation Factor 2 still separates them. Factor 2 mainly depends on the decomposition products of the polypeptide chain suggesting that the alkaline treatment and the natural aging alter the amino acid chain differently.
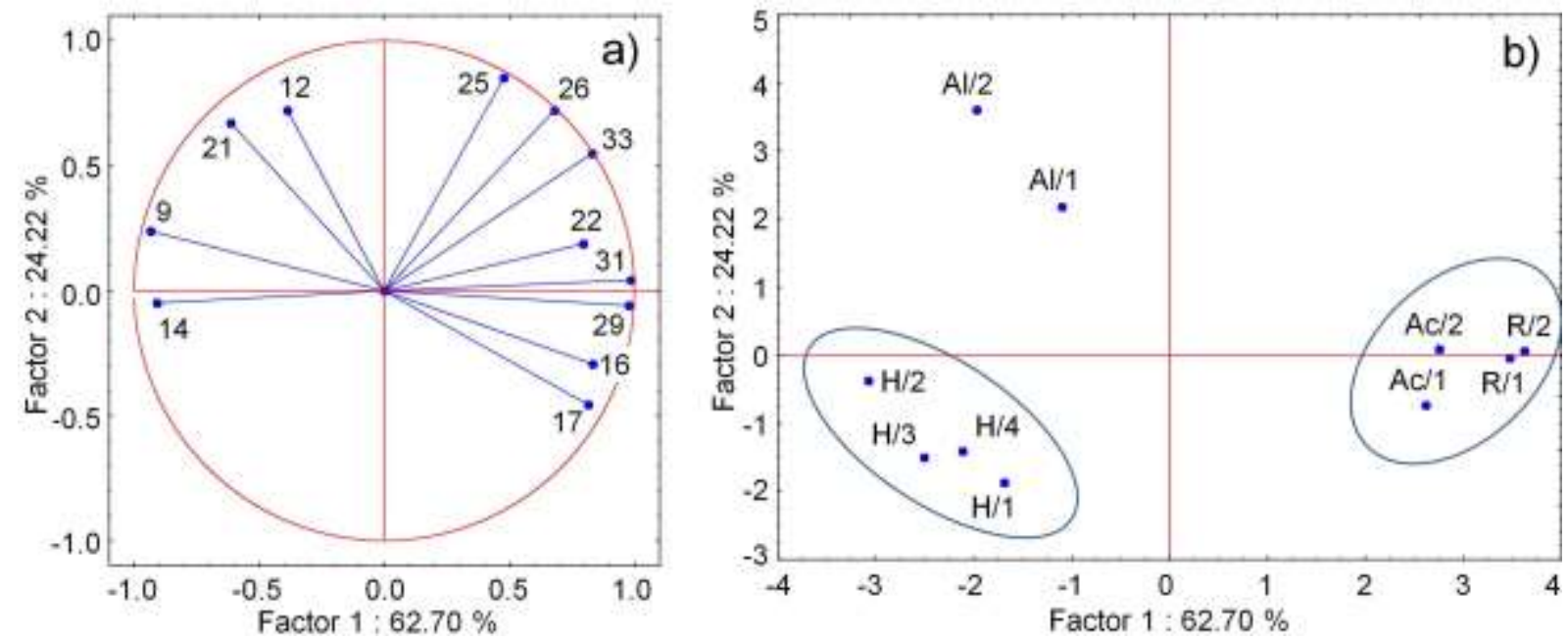

Fig. 6. PCA results: loading (a) and score (b) plots based on the Py-GC/MS results of the leather. R/1, R/2 new; Ac/1, Ac/2 acidic treated; Al/1, Al/2 alkaline treated; H/1, H/2, H/3, $\mathrm{H} / 4$ historical samples. Numbers refer to the decomposition products listed in Table 2. 


\section{Conclusions}

New, artificially aged and historical leather and parchment samples were measured by thermoanalytical techniques in order to monitor the changes in the chemical structure under acidic and alkaline treatments and compare them with those induced by the slow natural aging in historical samples. According to the thermogravimetric data, the decomposition of the naturally aged leather starts at lower temperature than that of the new sample while the thermal stability of the parchment samples changed to a smaller degree during the treatments. The maximum of the decomposition rate $\left(\mathrm{DTG}_{\max }\right)$ is lower in case of both naturally aged collagen-based materials. The increased carbon dioxide formation below $300^{\circ} \mathrm{C}$ indicates the partial oxidation of the samples during aging in both the artificially and naturally aged leather and parchment. The enhanced water evolution between 200 and $250^{\circ} \mathrm{C}$ might originate from the increased free hydroxyl groups or structural water.

The main decomposition products of the polypeptide chains under fast pyrolysis are diketopiperazines. The constant yields of the DKPs indicate the stability of the peptide bonds during natural aging and the applied aging treatments. However, the side groups might have been oxidized as the increased carbon dioxide and water evolution demonstrate. The distribution of the pyrolysis decomposition products of leather changed more significantly under natural or artificial aging comparing to that of parchments. The decomposition products affected by natural aging or alkaline treatment originate mostly from the vegetable tannin of leather. Phenol derivatives and aromatic compounds are the main markers of tannin; their intensity is considerably decreasing by degradation. Simultaneously, 1-vinylaziridine appears among the thermal degradation product of the historical leather and parchment and the alkaline treated samples as well. The results show that after the alkaline treatment the composition of the pyrolysis oil of leather became very similar to the historical samples.

PCA calculations revealed that the alkaline treatment modifies the tannin content of the newly produced leather similarly to the natural aging process, while the acidic treatment doesn't change significantly the composition of pyrolyzate comparing to the untreated leather sample.

\section{Acknowledgement}

This paper is based on some of the outcomes of the Bilateral Cooperation between Hungary and Romania Assessment and mitigation of impact of climate on library and archival heritage: experience, research, innovation (LIBER, CB 671/2013). The authors are grateful to the TÉT_12_RO-1-2013-0021, OTKA K 81959 and K83770 projects and "Bolyai János" research fellowship for the financial support. The authors are grateful to Prof. Károly Héberger for the help in the PCA calculation.

\section{References}

1. T. Kitahara, H. Ogawa, The extraction and characterization of human nail keratin, J. Dermatol. Sci. 2 (1991) 402-406.

2. S.H. Lee, K. Miyamoto, T. Goto, T. Oe, Non-invasive proteomic analysis of human skin keratins: Screening of methionine oxidation in keratins by mass spectrometry, J. Proteomics 75 (2011) 435-449.

3. S. Singh, S. Kumar, Numerical study on triple layer skin tissue freezing using dual phase lag bio-heat model, Int. J. Therm. Sci. 86 (2014) 12-20.

4. B. Zywicki, T. Reemtsma, M. Jekel, Analysis of commercial vegetable tanning agents by reversed-phase liquid chromatography-electrospray ionization-tandem mass spectrometry and its application to wastewater, J. Chromatogr. A 970 (2002) 191-200. 
5. E. Badea, G. Della Gatta, T. Usacheva, Effects of temperature and relative humidity on fibrillar collagen in parchment: A micro differential scanning calorimetry (micro DSC) study, Polym. Degrad. Stabil. 97 (2012) 346-353.

6. S. Jeyapalina, G.E. Attenburrow, A.D. Covington, Dynamic mechanical thermal analysis (DMTA) of leather. Part 1: Effect of tanning agent on the glass transition temperature of collagen, J. Soc. Leath. Tech. Ch. 91 (2007) 236-242

7. C.J. Kennedy, T.J. Weiss, The structure of collagen within parchment, Restaurator. 24 (2) (2003) 61-80.

8. J.E. Eastoe, The amino acid composition of mammalian collagen and gelatin, Biochem. J. 61(4) (1955) 589-600.

9. D.G. Arques, J.-P. Fallot, C.J. Michel, Identification of several types of periodicities in the collagens and their simulation, Int. J. Biol. Macromol. 19 (1996) 131-138.

10. A. Cucos, P. Budrugeac, Simultaneous TG/DTG-DSC-FTIR characterization of collagen in inert and oxidative atmospheres, J. Therm. Anal. Calorim. 115 (2014) 2079-2087.

11. A. Onishi, P.S. Thomas, B.H. Stuart, J.P. Guerbois, S. Forbes, TG-MS characterisation of pig bone in an inert atmosphere, J. Therm. Anal. Calorim. 88 (2007) 405-409.

12. B.A. Stankiewicz, J.C. Hutchins, R. Thomson, D.E.G. Briggs, R.P. Evershed, Assessment of bog-body tissue preservation by pyrolysis-gas chromatography/mass spectrometry, Rapid Commun. Mass Sp. 11 (1997) 1884-1890.

13. A. Adamiano, D. Fabbri, G. Falini, M.G. Belcastro, A complementary approach using analytical pyrolysis to evaluate collagen degradation and mineral fossilization in archaeological bones: The case study of Vicenne-Campochiaro necropolis, J. Anal. Appl. Pyrol. 100 (2013) 173-180.

14. P. Budrugeac, L. Miu, The suitability of DSC method for damage assessment and certification of historical leathers and parchments, J. Cult. Herit. 9 (2008) 146-153.

15. R. Larsen, Experiments and observations in the study of environmental impact on historical vegetable tanned leathers, Thermochim. Acta 365 (2000) 85-99.

16. P. Budrugeac, E. Badea, G.Della Gatta, L. Miu, A. Comanescu, A DSC study of deterioration caused by environmental chemical pollutants to parchment, a collagenbased materials, Thermochim. Acta 500 (2010) 51-62.

17. K.J. Voorhees, W. Zhang, A.D. Hendricker, B. Murugaverl, An investigation of the pyrolysis of oligopeptides by Curie-point pyrolysis-tandem mass spectrometry, J. Anal. Appl. Pyrol. 30 (1994) 1-16.

18. D. Fabbri, A. Adamiano, G. Falini, R. De Marco, I. Mancini, Analytical pyrolysis of dipeptides containing proline and amino acids with polar side chains. Novel 2,5-diketopiperazines markers in the pyrolysates of proteins, J. Anal. Appl. Pyrol. 95 (2012) 145-155.

19. A. Marcilla, A.N. García, M. León, P. Martínez, E. Bañón, Study of the influence of $\mathrm{NaOH}$ treatment on the pyrolysis of different leather tanned using thermogravimetric analysis and Py/GC-MS system, J. Anal. Appl. Pyrol. 92 (2011) 194-201.

20. J.B. Simić-Krstić, A.J. Kalauzi, S.N. Ribar, L.R. Matija, G.N. Misevic, Electrical properties of human skin as aging biomarkers, Exp. Gerontol. 57 (2014) 163-167.

21. S. Kurata, K. Ichikawa, Identification of small bits of natural leather by pyrolysis gas chromatography/mass spectrometry, Bunseki Kagaku 57 (7) (2008) 563-569.

22. V.J. Sundar, C. Muralidharan. A.B. Mandal, Eco-benign stabilization of skin protein Role of Jatropha curcas oil as a co-tanning agent, Ind. Crop. Prod. 47 (2013) 227-231.

23. S.V. Kanth, R. Venba, B. Madhan, H.K. Chandrababu, S. Sadulla, Cleaner tanning practices for tannery pollution abatement: Role of enzymes in eco-friendly vegetable tanning, J. Clean. Prod. 17 (2009) 507-515. 
24. E. Omen, G. Gulumser, S. Akay, O. Yesil-Celiktas, Optimization of tannin isolation from acorn and application in leather processing, Ind. Crop. Prod. 53 (2014) 16-22.

25. N.N. Fathima, A. Dhathathreyan, T. Ramasami, Influence of crosslinking agents on the pore structure of skin, Colloid. Surface. B 57 (2007) 118-123.

26. N.N. Fathima, M. Baias, B. Blumich, T. Ramasami, Structure and dynamics of water in native and tanned collagen fibers: Effect of crosslinking, Int. J. Biol. Macromol. 47 (2010) 590-596.

27. T.A. Centeno, J.J. Pis, J.A. Pajares, A.B. Fuertes, Microporous structure of chars produced by pyrolysis of preoxidized coals, J. Anal. Appl. Pyrol. 34 (1995) 13-28.

28. A. Marcilla, A.N. García, M. León, P. Martínez, E. Banon, Analytical Pyrolysis as a method to characterize tannery wastes, Ind. Eng. Chem. 50 (2011) 8994-9002.

29. C. Popescu, P. Budrugeac, F.J. Wortmann, L. Miu, D.E. Demco, M. Baias, Assessment of collagen-based materials which are supports of cultural and historical objects, Polym. Degrad. Stabil. 93 (2008) 976-982.

30. E. Badea, G. Della Gatta, P. Budrugeac, Characterisation and evaluation of the environmental impact on historical parchments by DSC, J. Therm. Anal. Calorim. 104/2 (2011) 495-506.

31. E. Zuriaga-Agustí, M.V. Galiana-Aleixandre, A. Bes-Piá, J.A. Mendoza-Roca, V. Risueño-Puchades, V. Segarra, Pollution reduction in an eco-friendly chrome-free tanning and evaluation of the biodegradation by composting of the tanned leather wastes, J. Clean. Prod. 87 (2015) 874-881.

32. R.S. Bhatnagar, Collagen, in Biochemistry and Human Biology, Prentice Hall of India Private Ltd., New Delhi, 2006.

33. A.D. Hendricker, K.J. Voorhees, An investigation into the Curie-point pyrolysis-mass spectrometry of glycyl dipeptides, J. Anal. Appl. Pyrol. 36 (1996) 51-70.

34. A.P. Case, C. Bizama, C. Segura, M.C. Wheeler, A. Berg, W.J. DeSisto, Pyrolysis of pre-treated tannins obtained from radiata pine bark, J. Anal. Appl. Pyrol. 107 (2014) 250-255.

35. J. Kaal, K.G.J. Nierop, P. Kraal, C.M. Preston, A first step towards identification of tannin-derived black carbon: Conventional pyrolysis (Py-GC-MS) and thermally assisted hydrolysis and methylation (THM-GC-MS) of charred condensed tannins, Org. Geochem. 47 (2012) 99-108.

\section{Highlights}

The thermal behavior of fresh and aged leather and parchment samples was compared.

Alkaline treatment and natural aging cause similar changes in the product distribution.

The unchanged yield of DKPs suggests the stability of the peptide bonds during aging.

The increased $\mathrm{CO}_{2}$ and $\mathrm{H}_{2} \mathrm{O}$ formation indicates the oxidation of side groups of collagen.

The tannin content of leather changes during alkaline treatment and natural aging. 